\title{
Determinants of Small-Scale Irrigation Use and its Effect on Household Food Security in Mirab Abaya Woreda, Southern Ethiopia
}

\author{
Masresha Tadesse, Tesfaye Samuel, Agidew Abebe* \\ Department of Rural Development and Agricultural Extension, College of Agricultural Sciences Arba Minch \\ University, Arba Minch, Ethiopia
}

*Corresponding Author: Agidew Abebe, Department of Rural Development and Agricultural Extension, College of Agricultural Sciences Arba Minch University, Arba Minch, Ethiopia

\begin{abstract}
In Ethiopia, agriculture is the primary determinant of economic growth and reducing level of food insecurity. But in the country in general and study area in particular, agriculture is dominated by small-scale rain-fed production. As a result, the current yield level by rural smallholder farmers in the study area has not been able to fulfill the minimum food requirements. To this end, this research aims to identify determinants of SSI use and its effect on household food security status in Mirab Abaya District, Southern Ethiopia. Multistage sampling technique and Kothari formula was employed to identify the final sample respondents; accordingly the final sample size was 168 (38.7\% irrigation users and 61.3\% non-users). Both quantitative and qualitative data from primary and secondary sources were collected through interview schedule. Descriptive, inferential statistics and binary logistic model were used to analyze the collected data. The finding of the study revealed that sex, education, household labor size, cultivable land size, frequency of extension contact, training and credit use had significant positive influence whereas farm distance from water source had significant negative influence on SSI use. Out of the total sample households, 72 (42.9\%) were food secure and 96 (57.1\%) were food insecure. The study result also reported, SSI had significant and positive influence on HFSS at 1\% level. Therefore, it is important to address factors affecting SSI use includes sex, education level, household labor size, cultivable land size, farm distance from water sources, training and also priority should be given to SSI development in planning and executing of policies and programs by all stakeholders.
\end{abstract}

Keywords: household, food security, binary, logit

\section{INTRODUCTION}

Majority of Ethiopia's farmers have been using traditional way of agricultural practices which is mostly rain fed. This has contributed for low productivity of the agricultural sector. To solve these problems, governmental and non-governmental bodies have made restless efforts to bring about change in agricultural production system. They have introduced improved agricultural technologies like use of fertilizers, high yielding varieties of seeds, pesticides and improved farm implements. However, the country has faced is low quantity and quality of irrigation based agriculture. This indicates that there are different factors directly or indirectly influencing the quality and quantity of agricultural production (Yishak, 2005).

Similarly, in the study area the delayed beginning of rainy seasons, early withdrawal and maldistribution of rain were challenges from which great lessons should be drawn to seriously look into expansion of small, medium and large scale irrigation in perspective. Dependence of most farmers on rain fed agricultural production system, poor agricultural water management at the irrigation scheme and household food insecurity especially in limited and erratic rainfall seasons are another problems the study area has been faced.

In other way, the soaring nature of household food insecurity in the study area has been reason to generate the need for this research. Hence, among different interventions undertaken by government to mitigate food insecurity in the area, irrigation farming is the one that is meant to cover for production inadequacies from the short and unpredictable rainy season. 
More importantly, the study area lacks of knowledge and empirical information regarding the major determinants of SSI use and whether food security of irrigation users is better off than those who depend on rain fall. Therefore, this study initiated to choose the study area and will reveal the seriousness of the problem and fill the gaps by analyzing the determinant of rural household's participation in small-scale irrigation and the contribution of small-scale irrigation on household food security status.

\section{OBJECTIVES OF THE STUDY}

The overall objective of this study focused on identifying the determinants of SSI use and its effect on household food security status in the study area.

The specific objectives of the study were:

1. To assess the status of small-scale irrigation in the study area.

2. To identify factors affecting Small-scale Irrigation use in the study area.

3. To examine the effect of Small-scale Irrigation use on household food security in the area.

\section{RESEARCH METHOdOLOGY}

Multi-stage sampling technique was employed to select the final sample respondents. First, Mirab Abaya Woreda was selected purposively based on the following reasons; the woreda has relatively better small-scale irrigation activities that give opportunity to government in developing modern small-scale irrigation schemes, the necessity of irrigation for the area due to high erratic rainfall in low land kebeles, the focus of government to increase agricultural production and productivity to ensure food security and absence of similar studies in the area. In the second stage, simple random sampling technique was used to select 3 kebeles from irrigation accessible kebeles. There are 13 irrigation accessible kebeles in the woreda which are found in lowland agro ecology. In the third stage, the sampling frame (complete village household lists) was obtained from each Kebele administration office and was stratified in to the two strata (irrigation user and non-user households). Since, each stratum is more homogeneous than the total population, we are able to get more precise estimates for each stratum and this enables to get a better estimate of the whole.

In the fourth stage, systematic random sampling technique was applied to select the sample respondents from each stratum at each kebele. Since, systematic sampling has certain plus points, and it can be taken as an improvement over a simple random sample in as much as the systematic sample spread more evenly over the entire population (Kothari, 2004).

The sample size for this study was determined through Kothari formula which is based on approach of precision rate and confidence level, the researcher has specify the precision that he wants in respect of his estimates concerning the population parameters. This approach is capable of giving the mathematical solution and as such a frequently used technique of determining ' $n$ '. Accordingly, the formula to find out the sample size (n) of finite population is:

$\mathrm{n}=\mathrm{z}^{2}$.p.q. $\mathrm{N} / \mathrm{e}^{2}(\mathrm{~N}-1)+\mathrm{z}^{2}$.p.q

Where, $\mathrm{N}=$ population $\mathrm{n}=$ sample size $\mathrm{z}=$ the value of standard variation at a given confidence level and to be worked out from table showing area under normal curve $p=$ sample proportion $q=1-p \quad e=$ given precision rate or acceptable error (Kothari, 2004).

In this study,

$\mathrm{N}=1716 \quad \mathrm{z}=1.96 \quad \mathrm{p}=0.15 \quad \mathrm{q}=1-0.15=0.85 \quad \mathrm{e}=0.05$

$\mathrm{n}=1.96^{2 *} 0.15^{*} 0.85 * 1716 / 0.05^{2}(1716-1)+1.96^{2 *} 0.15^{*} 0.85=168$

This sample size (168) was redistributed to each kebele via probability proportion to size through the following formula:

$\mathrm{n}_{\mathrm{i}}=\mathrm{N}_{\mathrm{i}} / \mathrm{N}^{*} \mathrm{n}$

Where, $\mathrm{n}_{\mathrm{i}}$ is number of sample $\mathrm{HH}$ from each kebele, $\mathrm{Ni}$ is the number of households in each kebele and $\mathrm{N}$ is the universe or total population. Data were collected through household survey, focus group discussion, key informant interview and field observation. 
After data were collected from both primary and secondary sources, it was entered to statistical software (SPSS-20). Prior to data entry and analysis, the data processing includes, data preparation (coding, editing and checks for errors and biases), counting (frequency of occurrences) and grouping of collected data was carried out. Descriptive, inferential and regression analysis were employed. The econometric model, binary logistic regression model was used to identify factors that affect small scale irrigation use and to realize whether irrigation practice has an influence on household food security status or not.

\section{RESUlt AND DISCUSSIONS}

\subsection{Status of Irrigation Use in the Study Area}

Traditional irrigation particularly, traditional river diversion in the area is one of the irrigation systems and it is simple for farmers to practice by inheriting the knowledge from grandparent. At present time, both traditional and modern small-scale irrigation systems are being practiced in low land parts of the study area. Modern irrigation scheme like canal river diversion are introduced and some farmers have also adopted irrigation technologies like motor pump (MAWANRM, 2019). The same source disclosed that currently, the total irrigation potential of the study area is 22,779 ha. However, from the total irrigation potential 9,893 hectare of land was covered with both traditional and modern irrigation (irrigated).

\subsubsection{Sources of Irrigation Water for Irrigation Users}

Information gathered from key informants and field observation indicated that major water sources for irrigation in this area include rivers like (Raya, Baso, Shafe and Tsilmate rivers), Lake Abaya and small springs (like Gegessa and Alabi springs). One of the water sources in the Woreda is ground water and the ground water table depth ranges from 6-108m.

The survey result revealed that most of irrigation user households in the study area 37 (56.9\%) and $20(30.8 \%)$ depend on rivers and lake respectively. Additional information gathered from FGD reported that, in the area, rivers especially in rainy season are available and accessible source of water for all irrigation users. But during dry season the volume of irrigation water from the rivers decrease and that farm land located far from these sources and downstream communities have less access to use irrigation water when compared with that farm land located nearest to the rivers and upper stream communities." Following to river respondents with farmland near to lake and others who contracted land near to lake uses it as source of irrigation water. There are less number of spring and well water users in the area.

Table1. Sources of irrigation water for irrigation users

\begin{tabular}{|l|c|l|}
\hline Sources of water & N & $\%$ \\
\hline River & 37 & 56.9 \\
Lake & 20 & 30.8 \\
\hline Well & 5 & 7.7 \\
Spring & 3 & 4.6 \\
\hline
\end{tabular}

Source: own field survey, 2019.

\subsubsection{Irrigation Water Diversion and Lifting Mechanisms in the Study Area}

Farmers in the study area use irrigation water through diverting from rivers and lifting from other sources through different types of water diverting and lifting mechanisms. The survey results show that out of the total irrigation users $41(63 \%)$ divert irrigation water through traditional diversion mechanism mostly through ditches, 18 (27.7\%) divert irrigation water by using motorized water pump and the remaining $6(9 \%)$ has used canal river diversion mechanism.

Table2. Irrigation water diversion and lifting mechanisms practiced by irrigation users

\begin{tabular}{|l|c|l|}
\hline Water diversion and lifting mechanisms & $\mathrm{N}$ & $\%$ \\
\hline Traditional diversion & 41 & 63 \\
\hline Motorized water pump & 18 & 27.7 \\
\hline Concrete canal Diversion & 6 & 9 \\
\hline
\end{tabular}

Source: Own field survey, 2019 


\subsection{Factors Affecting Small-Scale Irrigation Use in the Study Area}

Among the thirteen independent variables included in the model, eight variables had statistically significant influence on use of SSI. These variables are sex, education level, household labor size, cultivable land size, farm distance from water source, frequency of extension contact and irrigation and related training and credit use. The interpretation and discussion of each variable are indicated below:

Education level of the respondents: Educational level was found to be one of the vital factors that contributed to the use of SSI. Consistently to hypothesis, it had significant positive influence on the use of SSI at 5\% significance level. Other factors held constant, the odds ratio in favor of SSI use increases by a factor of 28.44 as the education level of respondent increased by 1 level. Household labor Size: The model result revealed that household size converted to adult equivalent had positive and significant influence on use of SSI at $10 \%$ level.

Total cultivable land size: Cultivable land size had significant positive influence on use of smallscale irrigation at 5\% significance level. All other things being kept constant, the odds ratio in favor of small-scale irrigation use increases by a factor of 144.983 as cultivable land size increased by 1 hectare.

Farm distance from water source: Farm distance from water sources had significant negative influence on use of SSI at $1 \%$ significance level. The odds ratio disfavors the use of irrigation by a factor of 0.002 as the farm distance from irrigation water source increased in $1 \mathrm{~km}$.

Frequency of extension contact: The number of contact with Development Agents per month had significant positive influence on irrigation use at 5\% significance level. Other things held constant, the odds ratio favors the likelihood to use irrigation by a factor of 18.126 as the respondents' number of contact with the Development Agents per month increased by a unit. Therefore, respondents who highly contact with Development Agents per month have more chance to practice small scale irrigation in the area.

Attendance on irrigation and related training: Attendance on irrigation and related training had significant positive influence on the use of SSI at 10\% significance level. Other things kept constant, the odds ratio in favor of irrigation use increases the likelihood by a factor of 151.389 for the respondents who attended irrigation and related trainings.

Table3. Maximum likelihood estimates of the binary logit model and its odds ratio on factors affecting SSI use

\begin{tabular}{|l|l|l|l|l|l|l|}
\hline Variables & B & S.E. & Wald & df & P-value & Odds Ratio \\
\hline Sex of respondent(1) & $2.661^{*}$ & 1.470 & 3.277 & 1 & .070 & 14.307 \\
\hline Age of respondent & .140 & .107 & 1.707 & 1 & .191 & 1.150 \\
\hline Education level & $3.348^{* *}$ & 1.588 & 4.444 & 1 & .035 & 28.441 \\
\hline Household labor size & $1.728^{*}$ & .910 & 3.603 & 1 & .058 & 5.628 \\
\hline Total household income & .000 & .000 & 2.521 & 1 & .112 & 1.000 \\
\hline Cultivable land size & $4.977^{*}$ & 2.094 & 5.646 & 1 & .017 & 144.983 \\
\hline Livestock holding in (TLU) & .450 & .673 & .447 & 1 & .504 & 1.568 \\
\hline Irrigation and related training(1) & $5.020^{*}$ & 2.901 & 2.994 & 1 & .084 & 151.389 \\
\hline Farm distance from water source & $-16.055^{* * *}$ & 5.747 & 7.806 & 1 & .005 & .002 \\
\hline Distance from nearby market & .561 & .663 & .717 & 1 & .397 & 1.753 \\
\hline Location of farm land & -1.502 & 1.545 & .945 & 1 & .331 & .223 \\
\hline Frequency of extension contact & $2.897^{* *}$ & 1.167 & 6.165 & 1 & .013 & 18.126 \\
\hline Credit use (1) & $3.888^{*}$ & 2.037 & 3.642 & 1 & .056 & 48.820 \\
\hline Constant & -15.655 & 7.841 & 3.986 & 1 & .046 & .000 \\
\hline
\end{tabular}

-2loglikelihood $=29.036$, correctly predicted user $=96.9 \%$, correctly predicted non-user $=99 \%$ and Overall prediction $=98.2 \%$.

$* * *, * *$ and $*$ Significant at $1 \%, 5 \%$ and $10 \%$ significant level respectively.

Source: Computed from own field survey, 2019. 


\subsection{The Effects of Small-Scale Irrigation on Household Food Security}

Out of the 13 explanatory variables 6 were found to have significant effect on household food security. These variables include SSI use, livestock holding, cultivable land size, total household income, farm distance from water source and distance from nearby market.

Small scale irrigation use: The model result reported that SSI had significant positive effect on household food security at $1 \%$ level, meaning that irrigation plays a major role in enhancing household food security in the area. The study result therefore revealed that, relative to non-users of irrigation, the likelihood to be food secure for irrigation user households increased by a factor of 6.516 all other things kept equal.

Livestock holding (TLU): As model result revealed, livestock size had significant positive effect on probability of being food secure at $5 \%$ level. The odds ratio indicated that as size of livestock holding increased by one TLU the likelihood of households to be food secure increased by a factor of 1.34 .

Total cultivable land size: The model result revealed that total cultivable land significantly and positively influences household food security at $10 \%$ level. This means those households who had larger cultivated land size are food secure than those having smaller land size. The odds ratio indicated that when the total cultivable land size increased by 1 ha, the likelihood to be food secure households increased by a factor of 1.72 .

Total household income/Year: The result of model reported that total household income positively and significantly affects households' food security at $1 \%$ level. The odds ratio in favor of being food secure is increased by a factor of 1 when the total annual income of household increased by 1 Birr. This result is consistent with the fact that more income improves the purchasing power, let farmers use modern inputs that improve their production and productivity and diversify their production activity.

Distance from nearby market: The result of model disclosed that market distance from farm households' house had significant negative effect on household food security at $10 \%$ level. The odds ratio revealed when the distance of households' house from nearby market increased by an hour, the likelihood of household to be food secure decreased by a factor of 0.687 .

Table4. The estimation result of the binary logistic regression

\begin{tabular}{|l|l|l|l|l|l|l|}
\hline Variables & B & S.E. & Wald & df & P-value & Odds Ratio \\
\hline Sex of respondents (1) & .626 & .397 & 2.483 & 1 & .115 & 1.869 \\
\hline Age of respondents & -.016 & .023 & .479 & 1 & .489 & .984 \\
\hline Education level & .062 & .231 & .072 & 1 & .788 & 1.064 \\
\hline Household labor availability & .205 & .195 & 1.109 & 1 & .292 & 1.228 \\
\hline Total household income & $.000^{* * *}$ & .000 & 19.049 & 1 & .000 & 1.000 \\
\hline Cultivable land size & $.543^{*}$ & .329 & 2.716 & 1 & .099 & 1.721 \\
\hline Livestock holding (TLU) & $.333^{* *}$ & .164 & 4.132 & 1 & .042 & 1.396 \\
\hline Irrigation use & $1.874^{* *}$ & .703 & 7.105 & 1 & .008 & 6.516 \\
\hline Irrigation and related training & .638 & .458 & 1.940 & 1 & .164 & 1.893 \\
\hline Farm distance from water source & $-1.267 * * *$ & .446 & 8.074 & 1 & .004 & .282 \\
\hline Distance from nearby market & $-.375^{*}$ & .194 & 3.736 & 1 & .053 & .687 \\
\hline Frequency of extension contact & .409 & .309 & 1.755 & 1 & .185 & 1.505 \\
\hline Credit use(1) & -.048 & .460 & .011 & 1 & .917 & .953 \\
\hline Constant & -2.099 & 1.458 & 2.071 & 1 & .150 & .123 \\
\hline
\end{tabular}

-2 loglikelihood $=169.512$, correctly predicted food secure $=69.4 \%$, correctly predicted food insecure $=84.4 \%$ and Overall prediction $=78.0 \%$.

$* * *, * *$ and $*$ significant at $1 \%, 5 \%$ and $10 \%$ respectively.

Source: Computed from own field survey, 2019.

\section{CONCLUSION AND RECOMMENDATIONS}

For the further development of the small scale irrigation and promotion of household food security status in the study area attention should be given towards the following points:

Use of small scale irrigation in the study area is determined by the sex of respondent, education level of respondent, household labor availability, total cultivable land size, farm distance from water source, attendance on irrigation and related training and credit use. Therefore: 
The government and other development partners working with rural households have to empower females, household labors and non-user male headed HHs to involve in irrigation activities through awareness creation and promoting credit accessibility by strengthening the involvements of MFI in agricultural development.

Education and agricultural sectors should give emphasis on training farmers through strengthening and establishing FTCs, technical and vocational schools to improve farmers' awareness on use of irrigation and adoption of irrigation technologies.

Attention should be given in improving the quality of land through improved soil and water management mechanisms, awareness provision for farmers to use farm land in a more productive way.

In the study area also farmers use rivers and lake as source of irrigation water. These sources were not accessible by most of farmers due to distance problem. Therefore, it is better to initiate farmers to develop other alternative sources like ran-off water harvesting technologies, ponds and ground water development.

The water and irrigation development sector should focus to convert traditional river diversion in to modern one for effective use of the existing river potential and establish WUA for better management. And an emphasis should be made to improve accessibility of motor pump for farmers to use lake water.

As the findings of this study assured, irrigation and food security are positively and significantly related in the study area. Therefore, development strategies and programs related with food security must not exclude the improvement of production and productivity of agricultural sector through use of irrigation.

Moreover, introducing, organizing and promoting livestock development packages (fodder production and medical services), diversification of household income through improving farmers' participation on on-farm and off-farm activities, irrigation water opportunities near to their farm land and improving market accessibility are another area of focus to be taken to overcome food insecurity in the study area.

\section{REFERENCES}

[1] ATA. (2014). Transforming Agriculture in Ethiopia. Annual Report of 2013/2014. Ethiopian Agricultural Transforming Agency, Addis Ababa, Ethiopia. Pp.8.

[2] Gujarati, D.N. (1995).Basic Econometrics. $3^{\text {rd }}$ Ed. McGraw-Hill Inc, New York

[3] Kothari CR (2004). Research Methodology, Methods and Techniques. $2^{\text {nd }}$ Ed. New Age International: University of Rajasthan, Jaipur.418pp.

[4] MoA. (2011). Small-scale irrigation capacity building strategy for Ethiopia. Natural resources Management Directorate through the support of GIZ MOA, Natural resource sector, Sustainable Land Management Program, Addis Ababa, Ethiopia.

[5] Rodrguez, G. (2007). Logit Models for Binary Data. [Internet]

[6] Tizita, D. (2017). The Effect of Small Scale Irrigation on Household Food Security in Bona-Zuria Woreda, Sidama Zone, Ethiopia. Msc Thesis (unpublished) presented to Hawassa University.

[7] Stanley Yokwe. (2009). Water productivity in smallholder irrigation schemes in South Africa. Agric. Water Manage, Vol. 96, 1223-1228.

Citation: Masresha Tadesse, Tesfaye Samuel, Agidew Abebe, "Determinants of Small-Scale Irrigation use and its Effect on Household Food Security in Mirab Abaya Woreda, Southern Ethiopia". International Journal of Research Studies in Biosciences. 2020; 8(8): 42-47. DOI: https://doi.org/10.20431/2349-0365.0808004.

Copyright: () 2020 Authors. This is an open-access article distributed under the terms of the Creative Commons Attribution License, which permits unrestricted use, distribution, and reproduction in any medium, provided the original author and source are credited. 